\title{
FRANCIS BACON Y LA IMITACIÓN DEL MODELO COLONIAL HISPANO
}

\author{
Francis Bacon and the imitation \\ of the Hispanic colonial model
}

\author{
FRANCISCO CASTILLA URBANO \\ Universidad de Alcalá \\ francisco.castilla@uah.es
}

Cómo citar/Citation

Castilla Urbano, F. (2021).

Francis Bacon y la imitación del modelo colonial hispano.

Revista de Estudios Políticos, 192, 37-65.

doi: https://doi.org/10.18042/cepc/rep.192.02

\section{Resumen}

El pensamiento de Francis Bacon (1561-1626) se ha relacionado más con el empirismo, la ciencia y la utopía, que con el colonialismo y el imperialismo. Sin embargo, tanto por el período en que le tocó vivir, por sus responsabilidades parlamentarias y de gobierno, como por sus gustos intelectuales, el Canciller estuvo siempre atento a las transformaciones económicas, sociales o militares de su mundo. Lo hizo, además, no con la indiferente mirada de un espectador, sino con el interés de un hombre consciente de los grandes avances que se estaban produciendo y de los cambios que generaban, pero, sobre todo, con la pretensión de que Inglaterra no se quedara atrás en su aprovechamiento. En este sentido, nadie en su época parece haber tenido tan clara la necesidad de fijarse en las acciones de los espańoles, como un modelo con el que competir y al que imitar.

\section{Palabras clave}

Francis Bacon; España; América; colonialismo; ciencia; leyenda negra.

\section{Abstract}

The thought of Francis Bacon (1561-1626) has been more closely related to empiricism, science, and utopia than to colonialism and imperialism. However, the 
Chancellor was always attentive to the economic, social or military transformations of his world, both because of the period in which he lived, because of his parliamentary and government responsibilities and because of his intellectual tastes. Furthermore, he did so, not with the indifferent eyes of a spectator, but with the interest of a man who was aware of the great advances that were taking place and the changes they generated, and, above all, with the determination that England was not left behind when it came to taking advantage of them. In this sense, no one in his time seems so aware of the need to look at the actions of the Spaniards, as a model with which to compete and to imitate.

\section{Keywords}

Francis Bacon; Spain; America; colonialism; science; black legend. 


\section{SUMARIO}

I. EL MUNDO HISPÁNICO COMO FOCO DE INTERÉS. II. CIENCIA E IMPERIALISMO. III. LA POLIITICA DE LA CONQUISTA. IV. UTOPÍA CIENTIIFICA Y RAZÓN CONSERVADORA. BIBLIOGRAFÍA.

\section{EL MUNDO HISPÁNICO COMO FOCO DE INTERÉS}

El pensamiento de Francis Bacon se ha relacionado más con el empirismo, la reforma del saber y la utopía, que con el colonialismo y el imperialismo. Cuando ha ocurrido esto, se recurre a un imperialismo más próximo a la ciencia (White, 1958: 489), el conocimiento (Irving, 2006: 261) o la filantropía (Clarke, 2008: 377) que al deseo de dominio de otros territorios y poblaciones; como si el sentido más propio del término le fuera ajeno. Sin embargo, tanto por lo cambiante del período en el que vivió, por sus responsabilidades parlamentarias y de gobierno, así como por sus gustos intelectuales, Bacon siempre atendió a las transformaciones económicas, sociales o militares que estaban teniendo lugar. No en vano, escribió acerca de los desarrollos de la navegación, las armas, los inventos más influyentes y sus aplicaciones y resultados; concedió una gran relevancia a la evolución del mundo desde los viajes de exploración del siglo xv, que culminan con la llegada de Colón a América, y quiso extraer sus consecuencias en todos los ámbitos. Lo hizo, además, no con la indiferente mirada de un espectador, sino con la pretensión de aprovecharlos para que Inglaterra no se quedara atrás en la configuración y reparto de los nuevos dominios. Esta actitud no era excepcional. Es frecuente en el mundo de las letras y alcanza su culminación en la literatura inglesa y francesa del siglo XVII (Fuchs, 2013; Cioranescu, 1983). Aparece igualmente en muchos filósofos y políticos casi desde que se tuvieron noticias del descubrimiento del Nuevo Mundo (Hart, 2001; Hillgarth, 2000; Schaub, 2003). En muchos de los compatriotas de Bacon se acentuó a causa de las acciones de los españoles en Europa y de los iniciales fracasos ingleses para establecer asentamientos en el Atlántico (Armitage, 2004a). La monarquía española se convirtió en un modelo con el que competir (Morales Lezcano, 1968) y al que a la vez imitar (Elliott, 2010).

Nadie parece haber extendido la comparación a tantos elementos como lo haría el Canciller. No obstante, aunque se ha señalado la familiaridad de Bacon con tratadistas españoles como Luis Vives, Gómez Pereira, Vallés, Sánchez y 
otros (Gómez-Tabanera, 1998: 252), prácticamente ninguno de sus estudiosos insiste en ello y, como si fuera necesario subrayar lo contrario, hasta se ha destacado su vacilación con el castellano por reproducir incorrectamente el proverbio "Desvario sempre con la calientura", de lo que se dijo que "Bacon demuestra que estaba menos seguro de su español que de sus juicios militares» (Marías, 1985: 217). Sin embargo, su familiaridad con lo español se manifiesta en múltiples registros: sus discursos parlamentarios e informes (Bacon, 1826: 203-307); el conocimiento de personajes célebres como la reina Isabel (Bacon, 1980: 202), el Gran Capitán (ibid.: 219) o el rey Alfonso X (ibid:: 210), cuyo detalle, como el reconocimiento de la valía del presidente de la Audiencia de Perú Pedro de la Gasca (ibid: : 175-176) o el dicho atribuido al virrey Antonio de Mendoza en sus Apophthegms new and old (Bacon, 1859: 131), según el cual "That the government of Peru was the best place that the King of Spain gave, save that it was somewhat too near Madrid», muestran mayor profundidad de la que podía ser habitual en su medio. Otros cronistas y pilotos que nombraremos más adelante son también representativos de esta familiaridad, pero merecen una atención específica sus lecturas del jesuita José de Acosta, cuya presencia en Bacon parece haber sido descubierta recientemente por Ivonne del Valle (2013: 440-441) en las notas de W. A. Wright a su edición del The Advancement of Learning (Bacon, 1926: 309-10), cuando la primera edición de esta obra por Wright es de 1868. Con anterioridad a Del Valle, lo había indicado Zagorin (1999: 256), aludiendo al prefacio de Robert Leslie Ellis a su edición de Bacon, Historia ventorum (Bacon, 1863: 194-195, no 94-95, como anota Zagorin). Ellis subrayó la amplia deuda del Canciller con el jesuita, visible también en el Novum organum (II, XXXVI; Bacon, 1985: 275).

Conocido es que ese interés está presente también en la elección del frontispicio de la primera edición de la Instauratio Magna (1620), que retoma grabados y motivos del Regimiento de navegación (1606) del cartógrafo del Consejo de Indias Andrés García de Céspedes (Pimentel, 2001: 24). En el Novum organum (I, XCIII; Bacon, 1985: 152, y véase Farrington, 1971: 91), Bacon sustituyó la leyenda Plus ultra, que en el español recogía el orgulloso lema que el rey Carlos había adoptado para expresar que sus posesiones del Nuevo Mundo habían roto los antiguos límites de las exploraciones, por la del incremento del conocimiento, extraída del libro de Daniel (12.4): «Multi pertransibunt et augebitur Scientia».

Con estos antecedentes sorprende que se pueda decir que «el barco es, sin lugar a dudas, un buque de guerra, y posiblemente de diseño inglés» (Martin, 2007: 134). Más aceptable parece afirmar que, al apropiarse del emblema carolino, Bacon estuviera lanzando un argumento audaz para una política imperial: una filosofía natural reformada ayudará a traer un imperio (Martín, 2007: 135). De la misma manera, también un nombre puede sugerir la gloria 
venidera: «Su alteza tiene un nombre imperial. Fue un Carlos quien trajo primero el imperio a Francia; un Carlos quien lo trajo primero a Espańa; ¿por qué no debería Gran Bretaña tener su turno?» (Bacon, 1826: 237).

Por lo demás, la atracción de Bacon por la iconografía de las columnas de Hércules es muy anterior a 1620. De hecho, ya en 1605 las relaciona con Jacobo I: «¿Qué razón hay para que unos cuantos autores prestigiosos se alcen a modo de columnas de Hércules, más allá de las cuales no se pueda viajar y descubrir, cuando en Vuestra Majestad tenemos una estrella tan luminosa y benigna para guiarnos y darnos fortuna?» (Bacon, 1988: 74). Sin pretender ser exhaustivo, también alude a ellas en el Prefacio a La gran restauración para expresar las limitaciones humanas al avance del saber (Bacon, 1985: 49): «Tienen hoy las ciencias sus columnas fatales, que hacen que los hombres no se vean excitados ni por el deseo ni por la esperanza a penetrar más profundamente». Todavía volvió sobre los límites sobrepasados en el Novum organum (I, LXXII; Bacon, 1985: 126): «En nuestro tiempo se han hecho manifiestas por doquier muchas partes del Nuevo Mundo y los límites extremos del Viejo».

Ha llamado menos la atención que las columnas también adornaban la obra de Bacon más célebre y editada durante el siglo xvir, la Sylva sylvarum (Rees, 1981: 387). Como es sabido, esta fue editada póstumamente, junto con la Nueva Atlántida, pocos meses después de la muerte de Bacon, en abril de 1626, por su capellán, William Rawley. Se han expresado dudas sobre si este respetó la voluntad del Canciller al publicarla y si fue fiel en la reproducción de sus contenidos (Rusu y Lüthy, 2017). Pero estas dudas no afectan al grabado que contiene las columnas, que si no fue elegido por Bacon, es difícil imaginar que no representara en gran medida su voluntad (Hutton, 2002: 52-53). En la Sylva sylvarum las columnas dóricas de la Instauratio se convierten en corintias y son traspasadas por una esfera que representa el mundo intelectual (Colclough, 2010: 189). Se simboliza así la superación de los límites del mundo antiguo y medieval por los nuevos saberes, una vez que ha tenido lugar su desvelamiento material (Ceceña, 2010).

Además de estas imágenes, la conquista española de América, sus formas de expansión y colonización, la organización de la sevillana Casa de Contratación, la misma división de los asuntos de Estado en consejos encargados de su tratamiento (Gascoigne, 2012: 223), el uso de la ciencia para las exploraciones, el control de los mares, conceptos jurídicos tan relacionados con los indios y con los pensadores españoles como el de guerra justa (Bacon, 1980: 87), e incluso el ascenso y previsible caída de su imperio (ibid:: 225), ocupan la mente de Bacon para su adecuación a los intereses de Inglaterra. Ese empeño puede vislumbrarse tanto en sus escritos científicos como en sus informes políticos (Manzo, 2010). Todos, por otra parte, muestran cómo la mirada 
hacia España y la forma española de organizar sus dominios y de incrementar su conocimiento atrae la atención de los rivales europeos y provoca propuestas y actuaciones donde la pretensión de alcanzar sus logros es un estímulo permanente (Eamon, 2019: 493).

Todas estas razones nos llevan a estudiar el pensamiento del Canciller sobre el modelo colonial hispano en relación con tres aspectos: su vínculo con la ciencia, con la política y con la utopía.

\section{CIENCIA E IMPERIALISMO}

La aportación de Bacon al conocimiento científico no se incluye en el ámbito de los descubrimientos y la experimentación, en el que apenas alcanzó relevancia, ni en el del método, pues el que propuso tampoco resultó válido; asimismo, la epistemología que habría de triunfar con el tiempo también fue opuesta a sus pretensiones (Solis Santos, 2018). Incluso está lejos de ser un acierto su resistencia a dar la importancia debida al tratamiento matemático de la ciencia (Manzo, 2001). Esto no significa que le faltaran razones para mantener su postura. Así, por ejemplo, para la matemática, su oposición tiene que ver con su concepción de esta como una ciencia auxiliar de una filosofía natural que piensa la naturaleza de manera esencialmente cualitativa (Kusukawa, 1996: 60). Según esto, como se indica en el Novum organum, la matemática «debe clausurar la filosofía natural y en modo alguno generarla o iniciarla» (I, XCVI; Bacon, 1985: 153-154); asimismo: «La investigación natural se desenvuelve de manera óptima cuando la parte física se concluye matemáticamente» (II, VIII; Bacon, 1985: 198). De aquí puede derivarse un papel nuevo, tal vez habría que decir diferente, para la matemática (Jalobeanu, 2014: 85). Pero lo que no aceptaba, porque lo consideraba una reducción apriorística e injustificada de la naturaleza, era otorgar prioridad al lenguaje matemático, como Galileo o Descartes (Rossi, 1990: 362). Para Bacon la realidad era mucho más rica que su mera representación cuantitativa (Granada, 1982: 84). La matemática concebida por Bacon está anclada al estudio de las cosas, no a su abstracción (Mori, 2016: 20). Todo ello contribuye a que se considere que «en términos de doctrina sustantiva, Bacon realmente no tiene mucho que ofrecer» (Gaukroger, 2004: 222).

Lo destacable en Bacon es su interés por el desarrollo y la práctica de la ciencia. Consideraba que de usar y transformar, hacer y actuar, no solo observar y comprender, vendría tanto el progreso en el conocimiento de la naturaleza como la solución a importantes problemas de la humanidad (Serjeantson, 2002: 84-85). Asimismo, su genérico empirismo ha ejercido más atracción y ha sido mucho más reivindicado que los modos concretos, 
imposibles de llevar a la práctica, en los que se basaba (Zagorin, 1999: 126-128). Además, el interés por la ciencia de Bacon se inserta en un universo de sentido más amplio que el que reclaman los partidarios de considerarla desde una perspectiva teórica, fruto de la aportación excepcional de los grandes genios (Koyré, 1999; Cohen, 1983). No hay en Bacon esa estimación de determinados momentos de la ciencia que, por su trascendencia, pasan a definir un campo de saber con nuevos métodos y presupuestos epistemológicos; ese es un modelo que se empieza a imponer tras su muerte y que desde hace tiempo está sometido a revisión (Shapin, 1996).

Por el contrario, Bacon insertó su propuesta de un nuevo método científico y su aplicación a la totalidad de la naturaleza en el marco de los viajes de exploración y de los consiguientes descubrimientos de rutas, tierras y personas que caracterizaban el proceso de expansión europeo; este, a su vez, necesitaba de teorías, instrumentos y medidas que contribuyeran a su afianzamiento (Camprubí, 2009). El Canciller se sirvió de lo que había en este proceso de ensanchamiento del mundo conocido para tomarlo como ejemplo para la ampliación del entendimiento humano (Rossi, 1996: 31). El conocimiento de gentes y lugares revelado por el Renacimiento le parecía un signo de la superioridad del saber de su tiempo sobre el de los antiguos, que no fueron capaces de diferenciar los pueblos de los que tenían conocimiento ni asomarse más allá de las tierras o mares que les eran más cercanos. Incluso, como recuerda en el Novum organum (I, LXXII; Bacon, 1985: 126), sus saberes se resintieron de estas limitaciones, atribuyendo inhabitabilidad a territorios que nunca habían visitado. A partir del siglo XVI, el contacto con distintos pueblos venía a proporcionar un conocimiento de la diversidad humana imposible de imaginar apenas cincuenta años antes. De la misma forma, la experiencia directa de la Zona Tórrida había permitido desechar mitos y leyendas sobre la realidad de la tierra. Poco más adelante, las ideas sobre los fenómenos físicos y astronómicos abrían paso a la adquisición de nuevos saberes de forma acelerada. Se hacía necesario, por tanto, extender ese conocimiento de los hechos antropológicos, geográficos y celestes a la totalidad de la experiencia, ampliando el ámbito de la epistemología heredada de la Edad Media. En este contexto reivindica Bacon los viajes y descubrimientos de su tiempo como un anticipo del aumento del intelecto, que habría de superar al de sus antecesores:

No se debe subestimar el hecho de que las largas navegaciones y viajes (que se han incrementado en nuestros días) han mostrado y permitido descubrir en la naturaleza muchas cosas que podrían arrojar luz a la filosofía. Por eso sería vergonzoso para los hombres que si el ámbito del globo material (es decir, de las tierras, mares, astros) se ha abierto e iluminado inmensamente en nuestra época, el globo intelectual permaneciera, sin embargo, clausurado dentro de 
los límites estrechos de los descubrimientos de los antiguos» (I, LXXXIV; Bacon, 1985: 139).

Su sentimiento de superioridad sobre los antiguos era solo parte de una convicción bien asentada en su pensamiento, en la que ocupaban un lugar decisivo los logros científicos y técnicos que permitieron la expansión europea; esos mismos logros eran para Bacon manifestación de la más elevada capacidad de pensar, observar y aplicar de los tiempos modernos sobre los pasados (Bacon, 1985: 55-56). Esto es lo que ha hecho del Canciller un precursor de la teoría del progreso, aun sin acertar con la forma de la ciencia venidera (Bury, 1971: 54-64; Maravall, 1986: 581-582; Nisbet, 1981: 165-169; Rossi, 1970). Tal vez porque Bacon vivió en un momento en el que todavía la obra de Copérnico no se mostraba como el aporte fundamental para la revolución científica, tendía a ver su propuesta como un componente más, que él mismo no deja de discutir, de un mundo que está cambiando sus pautas de interpretación (Kuhn, 1982: 73). No rechazaba la importancia de la teoría y se empeñó en establecer un método de conocimiento, pero siempre otorgó un valor más trascendente a una serie de descubrimientos e invenciones. Atribuía la superioridad del mundo moderno sobre el antiguo y la del europeo sobre el resto de los países, más a esas aplicaciones donde las técnicas jugaban un papel fundamental, que a cualquier otro elemento:

Además vale la pena tomar nota de la fuerza, la virtud y las consecuencias de los inventos, especialmente manifiestas en aquellos tres inventos desconocidos de los antiguos y cuyo origen, aunque reciente, es obscuro e ignoto; me refiero a la imprenta, la pólvora y la brújula. Estas tres cosas han cambiado la faz del mundo y las condiciones de la vida humana: la primera en el campo de las letras, la segunda en el ámbito de la guerra y la tercera en la navegación. Ellas han causado innumerables cambios, de forma que ningún imperio, ninguna secta, ninguna estrella parece haber ejercido mayor eficacia y mayor influjo sobre las cosas humanas del ejercido por estos inventos mecánicos (I, CXXIX; Bacon, 1985: 184).

A la vez, frente a los que identifican la filosofía baconiana de la ciencia con la reivindicación de la experiencia por encima de cualquier otro valor, hay que señalar que también veía en las expediciones y descubrimientos el triunfo de la conjetura, de la convicción previa en las posibilidades de una hipótesis. Por eso, la combinación de especulación y constancia del descubrimiento colombino se le ofrecía como un ejemplo a imitar por los científicos:

Hemos de abrir y proponer nuestras conjeturas, base de una esperanza probable en este asunto, tal y como hizo Colón, el cual —antes de su maravillosa travesía 
del mar Atlántico- dio las razones por las que confiaba en poder descubrir nuevas tierras y continentes, distintos de los anteriormente conocidos, razones que, aun rechazadas en un primer momento, quedaron confirmadas después por la experiencia y fueron causa y comienzo de grandes eventos (I, XCII; Bacon, 1985: 151).

Si equiparaba la acción de los descubridores a la actividad científica, no debe extrañar que incluyera a Colón, por quien siempre tuvo verdadera admiración, entre los inventores célebres que, representados mediante una estatua, eran objeto de culto en la Nueva Atlántida:

Tenemos entre ellas la estatua de vuestro Colón, que descubrió las Indias Occidentales, la del inventor de las naves, la de aquel monje vuestro que inventó la pólvora y la artillería; la del inventor de la música, la del que inventó las letras, la del que inventó las observaciones astronómicas, del inventor de los trabajos en metal, del inventor del vidrio, de los gusanos de seda, del vino, el del maíz y el pan, del inventor de los azúcares (Bacon, 1996: 272).

La inclusión del Almirante entre los grandes hombres que legaron las pruebas de su ingenio a la humanidad muestra también la idea de experiencia manejada por Bacon. El empirismo que reivindicaba era el que suponía el primado de la obra, de la acción útil, una contribución que no tenía reparo en contraponer a las "ciencias racionales y dogmáticas", esto es, a la filosofía escolástica y a lo que consideraba especulaciones sin aplicación directa (I, LXXXV; Bacon, 1985: 141; Rossi, 1990: 318). Hay en el fondo del pensamiento baconiano un reconocimiento de la superioridad del valor práctico de cualquier descubrimiento o invención por encima del desarrollo teórico en sí mismo. Por eso, considera pernicioso que se atienda a los discursos y no a las obras (I, LXVI; Bacon, 1985: 117). Se ha dicho que esta actitud está influida por la doctrina de la predestinación (Elena, 1983: 111). Lo más relevante de la misma, sin descartar lo que pueda haber de satisfacción psicológica individual, es su entrega a los demás, esto es, que reconoce como una función fundamental de las artes y las ciencias, quizá la primordial, la mejora de la situación humana (II, LII; Bacon, 1985: 366). Esta misma concepción la aplica también Bacon a la historia, opuesta en su tratamiento de lo ordinario a la poesía o "historia ficticia», ocupada de lo fabuloso o imaginario (Ferraz Martínez, 2000). La historia es para el Canciller, como lo era para Maquiavelo, un instrumento para proporcionar enseñanzas a quienes se dedican a la vida pública. En un segundo plano queda que sea rigurosa en la elección de las fuentes o precisa en la descripción de lo exactamente ocurrido (Manzo, 2014: 391). 
La estimación del valor utilitario del conocimiento no lleva a desentenderse de sus fundamentos teóricos, pero Bacon reivindica una y otra vez lo que denomina artes liberales o mecánicas, y que no son sino las tecnologías o técnicas. Esta preferencia acerca sus ideas a lo que se considera la forma ibérica de concebir la ciencia por esta época (Barrera-Osorio, 2006: 2; 2008). A la vez, pone en un segundo plano e incluso permite cuestionar el contraste que se pueda establecer entre la visión baconiana, identificada con una concepción del conocimiento encaminada al pacífico dominio del hombre sobre la naturaleza, y una tradición que estaría basada en el conocimiento producido para el control del Nuevo Mundo (Pimentel, 2001: 24). Las prácticas científicas desarrolladas en el mundo ibérico durante los siglos XVI y XviI eran dependientes de las pretensiones imperiales de las monarquías ibéricas e iban asociadas en muchos casos a acciones donde la violencia y la imposición estaban presentes, pero dieron lugar al desarrollo de conocimientos, instrumentos e instituciones de todo tipo que sirvieron de modelos a otros países (Sánchez y Leitão, 2017a, 2017b).

Tal vez por su amplia experiencia política, Bacon puede acercarse a lo relacionado con la monarquía hispánica sin recurrir a los argumentos propagandísticos de la leyenda negra que iban a enarbolarse tanto desde su país (Maltby, 1982; Sanchez, 2004) como desde el resto de Europa (García, 1992; Villaverde y Castilla, 2016). En sus argumentaciones no falta espacio para el reproche - no en vano, como se ha dicho, «su potencial oponente era casi siempre España» (White, 1958: 480)—. Pero, resuelto a favorecer el proceso de expansión inglesa, no se deja impresionar por las experiencias que parecen haber afectado a algunos de sus compatriotas más célebres cuando se imaginaron a sí mismos actuando en América (Scanlan, 2008: 219).

La admiración de Bacon por el imperio español y su afán tanto mimético como emulador tenía como fundamento el éxito, lo que él mismo vino a denominar grandeza en las acciones llevadas a cabo por los reinos y Estados (Serjeantson, 2014, al margen de su hipótesis sobre la conquista de los Países Bajos). En esa grandeza estaba implícita la resolución de los problemas que había exigido su consecución (Bacon, 1980: 122-134). Su sensación era que España sabía manejarse al resolver los problemas prácticos que demandaban las exploraciones, la conquista y la asimilación de nuevas realidades (Madrid, 2013 y 2010). El concepto de ciencia asociado a esos logros podía limitar su consideración, pero estaba lejos de constituir un defecto (Lamb, 1985: 61). Para el Canciller, la contribución hispana al desarrollo de esta técnica mediante aportaciones náuticas, cartográficas, agrícolas, metalúrgicas, militares, organizativas, urbanísticas, médicas, de historia natural, etc., era garantía de éxito tanto en las exploraciones y conquistas como en la dirección política (Cañizares-Esguerra, 2006: 18). 
Lo que Bacon quería era adaptar los fundamentos de ese éxito a su propio país y encaminarlo adecuadamente para que alcanzara su propia grandeza. Todavía es necesario establecer de manera más precisa cuándo y cómo se produce ese proceso (Nieto Olarte, 2009). Pero de lo que no hay duda es de su existencia y de la coincidencia de procesos en ambas monarquías, como el de codificación de leyes, con la consiguiente influencia sobre la determinación de lo que es un "hecho" y la atribución de poder al Estado, que contribuyeron al mismo (Portuondo, 2009: 137-138). Todavía en 1663, menos de cuatro decenios después de la muerte del Canciller y como asumiendo sus aspiraciones, una institución de inspiración baconiana como la Royal Society, en cuyos orígenes jugó su papel una cierta dosis de nacionalismo (Elena, 1986a), recibía del rey y hacía suya la proclamación de la unión de ciencia e imperialismo: «Tenemos largo y plenamente resuelto extender no sólo los límites del imperio, sino también las de las artes y las ciencias» (Gascoigne, 2009: 539). Esta pretensión va mucho más allá de ser una mera cuestión de conocimiento (Irving, 2007).

\section{LA POLÍTICA DE LA CONQUISTA}

Bacon no dudaba de la superioridad de los europeos sobre los pueblos americanos. Atribuyó a los indios un salvajismo que hacía imposible aceptar sus formas de vida. En diferentes momentos y obras, proporcionó explicaciones para avalar esta opinión. Una de ellas tiene que ver, precisamente, con su admiración por la ciencia. En el siglo XviII, Montesquieu, Raynal, De Pauw, Robertson, Buffon y otros ilustrados pretendieron justificar la inferioridad americana desde las diferencias naturales, climáticas o antropológicas (Gerbi, 1993). La concepción baconiana de los habitantes del Nuevo Mundo se basaba en su propia cultura. Fue su admiración por los avances técnicos de la Europa de su época la que le sirvió para establecer su clasificación de los pueblos:

Considérese también la diferencia existente entre la vida humana en algún país muy civilizado de Europa y alguna región especialmente salvaje y bárbara del Nuevo Mundo; se encontrará a esta última tan inferior a la primera que se podrá decir con razón que «el hombre es un Dios para el hombre», no sólo por la ayuda y beneficios que puede hacer a otro hombre, sino también por la diferencia de condición. Y eso no es consecuencia del suelo, del cielo, de los cuerpos, sino de las artes (I, CXXIX; Bacon, 1985: 183-184).

Bacon creía que «el imperio humano sobre el universo reside solamente en las artes y en las ciencias, pues no es posible vencer la naturaleza más que 
obedeciéndola» (I, CXXIX; Bacon, 1985: 184). De aquí que pensara que el desarrollo científico y técnico constituía la base de las diferencias entre los pueblos. Esto no significa que valorara esos conocimientos como fuente de dominio o de explotación de los pueblos inventores sobre los que no lo eran. La famosa afirmación del Novum organum según la cual «la ciencia y el poder humanos vienen a ser lo mismo» (I, III; Bacon, 1985: 88), no quiere expresar, al menos en su sentido más genuino, que el conocimiento científico produce el dominio político, sino que es la ciencia la que da a la humanidad las mayores posibilidades de actuación en el mundo. Bacon siempre estimó que, a diferencia de los beneficios políticos, «los beneficios de los inventos pueden extenderse a todo el género humano» (I, CXXIX; Bacon, 1985: 183). Desde esta perspectiva, la ambición científica, que permitía descubrir nuevas técnicas y objetos útiles, resultaba legítima porque iría en provecho de toda la humanidad. No obstante, el Canciller era consciente de que el carácter práctico del saber científico otorga a quien lo posee un dominio de la realidad del que carecen los que desconocen la ciencia. Dicho de otro modo, la superioridad científica europea podía justificar su primacía sobre el mundo hasta que el resto de los pueblos alcanzasen la familiaridad debida con sus técnicas.

La inferioridad técnica y cultural de los aborígenes americanos era un efecto de las catástrofes que habían ocurrido en aquel continente. Bacon consideraba tres tipos de grandes desastres en la historia del mundo: diluvios, terremotos e incendios (con los que relacionaba las sequías). Aunque suponía que los incendios, efecto de los rayos, eran bastante frecuentes en América, la catástrofe que le parecía que había podido influir más en el estado de esas tierras y su población, es «un diluvio local, ya que los terremotos apenas se dan en aquellas partes; pero, en cambio, tienen ríos tan caudalosos que los ríos de Asia, África y Europa son sólo arroyos junto a ellos» (Bacon, 1980: 221). Bacon (1996: 247) rechazaba, por tanto, la versión platónica del terremoto como causa de la pérdida de la Atlántida, «que llamáis América». Convencido de la superioridad de los modernos sobre los antiguos, creía más en los cronistas españoles de Indias como Pedro Cieza de León, Pedro Sarmiento de Gamboa, José de Acosta y el mismo Antonio de Herrera, que discutieron sobre si un diluvio particular, además del universal del que solo Noé y los suyos escaparon, pudo tener lugar en América. Ese diluvio habría sido la causa de su poblamiento humano después de que los hijos del patriarca extendieran su progenie por el resto del mundo tras el primer diluvio (González Díaz, 2012: 506-9).

Para Bacon, un diluvio local posterior al de Noé avalaría la juventud de los pueblos indios frente a los del Viejo Mundo, y explicaría a la vez el desconocimiento de su pasado, pues «el remanente de gente que sobrevive es, por lo general, ignorante y montañeses que no pueden dar cuenta de los tiempos 
pasados; así que el olvido es completo como si no hubiera quedado nadie» (Bacon, 1980: 221). El Canciller adornó con nuevos detalles esta explicación, aclarando que el diluvio no solo despobló la Atlántida, sino que hizo de los pobladores de aquel territorio «un pueblo joven, por lo menos mil años más joven que el resto del mundo, ya que tanto ha sido el tiempo transcurrido entre el diluvio universal y esta su inundación» (Bacon, 1996: 249). Esta identificación de América con la Atlántida, encaminada a explicar la situación de atraso tecnológico de los pueblos americanos respecto de los europeos, corrige la indefinición de Bacon en el Novum organum: "Carece de importancia si el Nuevo Mundo es la isla de Atlántida ya conocida por los antiguos o un continente nuevo descubierto ahora por primera vez. El descubrimiento de las cosas se ha de buscar en la luz de la naturaleza y no en las tinieblas de la antigüedad» (I, CXXII; Bacon, 1985: 176).

De esta manera, Bacon también tomaba partido en el debate que mantuvieron los cronistas españoles sobre la existencia o no de la Atlántida y de su identificación con el Nuevo Mundo. Para Agustín de Zárate, este territorio constituía una isla distinta de las Indias, mientras que Pedro de Sarmiento sostuvo que el territorio aludido por Platón formaba un solo continente con el Nuevo Mundo, que se hundió después de permitir el tránsito de personas y animales desde Eurasia (González Díaz, 2012: 506). La opinión de Bacon coincide con la de Francisco López de Gómara que, en el capítulo CCXX de su Historia General de las Indias afirma que "podemos decir cómo las Indias son las islas y tierra firme de Platón» (1978: 314). Se enfrenta, por otra parte, a las argumentaciones de autores tan tenidos en cuenta por él como el jesuita Acosta, que rechazaba esta identidad en el primer libro, capítulo 22, de su Historial Natural y Moral de las Indias (2008: 38-40), y de Antonio de Herrera, que, en el libro primero, capítulo I, de la primera década de su Historia general de los hechos de los castellanos, parecía considerar toda la cuestión mera especulación, puesto que "cierta cosa es, que nadie tuvo noticia clara, y si alguno hubo, fueron rastros y vislumbres, interpretadas después del descubrimiento» (1601: 2).

Así pues, Bacon daba una explicación de la rudeza e ignorancia de los indígenas americanos en términos históricos. La razón del retraso de sus conocimientos con respecto a los de Europa no era su naturaleza defectiva o el clima americano, sino ese diluvio particular de América más reciente que el universal, que provocó la muerte por inundación o por la falta de comida consiguiente, de los habitantes de los valles, los más civilizados y avanzados en sus costumbres y saberes. Los hombres de los Andes o montañas «mucho más altas que las nuestras» que se salvaron, no tuvieron unos héroes culturales como Noé y sus hijos, que pudieran "dejar a la posteridad escrituras, obras de arte, ni ningún indicio de civilización» (Bacon, 1980: 221). Incluso la desnudez posterior se 
explica por su hábito de protegerse del frío extremo de las montañas con pieles de animales, «ignorando los medios para proporcionarse vestiduras ligeras» cuando bajaron a los valles: el exceso de calor les obligó a quedarse exclusivamente con los adornos de plumas que reflejaban su admiración por las aves (Bacon, 1996: 249-250).

Aunque esta explicación permite suponer que cuando se resuelvan los efectos de su diluvio se podrán equiparar con los europeos, parece evidente que, mientras tanto, les corresponde someterse a su conocimiento superior. La mirada baconiana del indígena americano aparece así llena de etnocentrismo: ve a los indios como sujetos más ignorantes que los europeos y también inferiores en su forma de vida. Por eso se ofrecen como objeto de conquista y ve en sus tierras una oportunidad para la expansión, lo que permitiría a Inglaterra equipararse con España en la construcción de un imperio.

Para imitar al imperio hispano, Bacon no reparó en consideraciones morales. Es cierto que se separó de Maquiavelo en diversos aspectos (Clarke, 2008), pero asumió lo esencial de la tradición maquiavélica adaptándola a sus circunstancias: consideraba que no debía poner obstáculos de conciencia a las metas políticas que su pensamiento había establecido para Inglaterra (Peltonen, 1996: 305). Todo aquello que atribuía a los españoles, le parecía que podía ser válido para su país, incluyendo lo que habría de ser objeto de mayores críticas en el siglo XVIII. Así, la tradicional oposición entre el dominio español de América y el de países como Inglaterra, Holanda e incluso Francia en cualquier lugar del mundo, se expresa, a partir sobre todo de Montesquieu, como una oposición entre imperio de conquista e imperios de comercio (Castilla Urbano, 2015). El primero, al que se atribuye un carácter premoderno, estaría basado en la posesión de la tierra, mientras que los segundos, típicamente modernos, se asentarían sobre patrones marítimos y comerciales (Castilla Urbano, 2014; Armitage, 2004b: 100-124). De acuerdo con esta distinción, para conseguir sus objetivos, los españoles habrían recurrido a una política destructiva para los indios, en la que la violencia sería habitual; por el contrario, en este contrapunto idealizado, la colonización inglesa tendría como valor fundamental la consecución de la prosperidad de los pueblos indígenas (Macmillan, 2011: 62). Es la política que, con el advenimiento del mundo contemporáneo, dominará al resto de los pueblos en nombre de la civilización y el progreso.

Se comete un error cuando se argumenta que «Bacon, aunque no fuera directamente responsable de estas reivindicaciones específicas, abre la vía para su argumentación» (Clarke, 2008: 377). Fue mucho más allá. Supo ver la importancia del comercio y, aunque era consciente de que el rey podía no obtener mucho provecho de los impuestos sobre el mismo, sabía que sin comerciantes su reino se empobrecería (Bacon, 1980: 89-90). También reconoce las 
virtudes del comercio y del tráfico marítimo, hasta el punto de valorar más, en una línea que entronca con los argumentos de arbitristas e ilustrados, las manufacturas y el transporte a las materias primas (ibid.: 72). Tampoco se le escapaba que los tributos eran necesarios para el funcionamiento del Estado, aunque sabía que su exceso podía volverse contra los afanes imperialistas de aquel (ibid:: 125).

En resumen, Bacon no desconocía los fenómenos económicos de su tiempo y los efectos que estos podían causar en el estado y en sus posibilidades de paz, prosperidad y expansión. También dedicó su atención a la importancia del poderío marítimo para el dominio de Europa y las Indias (ibid.: 132), consciente, como dice en las «Consideraciones sobre una presunta guerra con España», de que «su grandeza [la de la monarquía española] puede ser dividida en dos partes por una potencia que la aventaje en los mares» (Bacon, 1968: 139). Anticipó con ello otro de los tópicos ilustrados (Montesquieu, 1980: XXI). Sin embargo, la importancia del comercio y del control de los mares no interfería su concepción del imperio y la grandeza de los Estados (Peltonen, 1992).

El Canciller no llegaba tan lejos como Maquiavelo, que valoraba la riqueza del Estado pero la consideraba un obstáculo para el compromiso cívico si estaba en poder de los ciudadanos (Maquiavelo, 2005: 127, 255, 370 y 391). No se oponía al desarrollo de los valores comerciales, sino que, como hemos visto, los consideraba útiles para el Estado. Pero los ideales que quería poner en la base de su imperio sońado no eran aquellos, sino los militares. Por eso, como Maquiavelo (2005: 69, 391-394), consideraba más valiosa una población volcada sobre las labores del campo y los oficios que más se relacionan con estas, que siempre ofrecen buena disponibilidad para la guerra, que la dedicada a «las artes sedentarias y caseras y las manufacturas delicadas (que más requieren los dedos que los brazos)»(Bacon, 1980: 128). Incluso proponía «dejar libremente el ejercicio de esas artes a los extranjeros» (ibid.: 129). De hecho, para poner límites a la ideología comercial, considera que la colonia estará mejor gobernada si dependía de nobles y caballeros que de comerciantes, "pues éstos siempre miran a la ganancia presente» (ibid.: 143).

Así, pues, la acusación tantas veces formulada contra España durante el siglo XviII era reivindicada por Bacon como la política más válida para Inglaterra un siglo antes. La razón es clara: «Para el imperio y la grandeza lo que más importa es que la nación profese las armas como su principal timbre de gloria, de preocupación y ocupación». A Bacon se le ofrecían multitud de ejemplos del pasado (Roma, Esparta, los persas y macedonios, los galos, germanos, godos, sajones, normandos, etc.), mientras que en su presente consideraba que la virtud y la aplicación de las armas, la tenían los turcos, aunque en gran decadencia. El verdadero modelo contemporáneo en el que el Canciller ponía sus ojos era, de nuevo, España: 
De la Europa cristiana, los únicos que la tienen efectivamente son los españoles; pero es tan claro que cada uno progresa en lo que más se propone, que no es necesario insistir más. Es suficiente con señalar que ninguna nación que no profese directamente las armas puede esperar que venga a parar a sus manos grandeza alguna; y que, por otra parte, el oráculo más certero del tiempo es que aquellos Estados que persisten en esa profesión (como principalmente han hecho romanos y turcos) hacen maravillas; y aquellos que han profesado las armas, pero solo durante una época, generalmente han conseguido la grandeza en esa época que luego les ha mantenido durante largo tiempo aun cuando su profesión y ejercicio hubiera decaído (ibid.: 129-130).

Desde esta perspectiva, no sorprende que considerase que no son las ciudades amuralladas, los arsenales y armerías, las razas de caballos, los carros de guerra, los elefantes, las municiones, la artillería e incluso el dinero; ni siquiera le parecía decisivo el número de ejércitos, sino que «el punto principal de la grandeza de cualquier Estado está en tener una estirpe de militares» (ibid.: 124). Unos militares valientes, pero también nativos, pues Bacon, de nuevo en coincidencia con Maquiavelo (1978: 131-132; 2005: 143-1444 y 259-261), creía que el recurso a las tropas mercenarias llevaba tarde o temprano al desastre (Bacon, 1980: 125).

El Canciller siempre asoció la guerra con el incremento de población (ibid.: 225). Pensaba que una política de ciudadanos en armas exigía una población importante que, con frecuencia, el país no tenía. Por eso consideró que la naturalización de extranjeros podía ser un requisito ineludible, siempre que los naturales se mantuvieran como mayoría. El mejor ejemplo de la validez de esta afirmación lo extraía Bacon de la Antigüedad: comparaba Esparta y Roma, para concluir que la primera no había podido llevar adelante su imperio por su restrictiva política demográfica; en cambio, atribuía esta habilidad en grado sumo al Imperio romano, de manera «que no fueron los romanos los que se expandieron sobre el mundo, sino el mundo sobre los romanos». Sin embargo, la reflexión sobre los modelos históricos constituía solo una introducción al análisis de la situación de su tiempo. Era, sobre todo, la contemporánea España, la que, una vez más, se le ofrecía como un modelo de savoir faire en la gestión del imperio por su capacidad de movilizar ejércitos compuestos por tropas de origen diverso:

Algunas veces me ha maravillado cómo España puede abarcar y conservar tan grandes dominios con tan escasos españoles; pues seguro que el área de Espańa es un gran tronco de árbol muy superior al de Roma y Esparta al principio; y además, aunque no han utilizado esa libertad en la naturalización, no obstante, tienen lo que está muy cerca de ella; es decir, emplear, casi indiferentemente, 
todas las naciones en su milicia de soldados; incluso, algunas veces, en sus jefes de mayor graduación (ibid.: 128).

Esta admiración posee un claro carácter instrumental. Bacon no se siente escandalizado por la acción española ni en Europa ni en América. Su interés le lleva a dirigir su mirada a la capacidad de los españoles para conseguir sus objetivos. Quiere que la colonización inglesa persiga las mismas metas y señala los obstáculos que pueden impedirlo; de ahí las consideraciones económicas, organizativas, militares o demográficas, tendentes todas ellas a alcanzar el imperio. Rechaza una conquista sangrienta y la apropiación de tierras indias, pero es consciente de que las posibilidades de la colonización que postula pasan por esa desposesión. Por eso, precisa con detalle la manera de conseguirla sin escándalo, lo que no quiere decir sin injusticia ni sufrimiento.

Bacon era partidario de instalar la colonia "en un suelo puro, es decir, donde la gente no se haya desarraigado de un sitio para arraigar en otro; porque eso es más una extirpación que una colonización» (ibid.: 140). Pero esta manifestación no era más que la expresión de una buena intención, puesto que toda colonización requiere de gentes procedentes de la metrópoli. Más importancia tiene que en la costa atlántica norteamericana, donde se desarrollaba la colonización inglesa, no existían realmente las tierras no habitadas. Bacon todavía no lo mencionaba por su nombre, vacuum domicilium o terra nullius, lo que sería una constante del pensamiento británico posterior (Corcoran, 2018). Tenía, no obstante, muy claro el concepto: se trataba de un territorio no cultivado ni poblado de forma sedentaria del que los indios disponían según su interés. En esas condiciones, la apropiación de la tierra por los colonos implicaba siempre una expropiación para los indígenas.

Bacon no hizo de esto un problema y ni siquiera se puede decir que desechara abiertamente la conquista de las tierras indias. Su deseo de hacerse con territorios donde instalar una colonia era claro, aunque se expresara de manera un tanto ambigua: no descartaba la colonización donde hubiese indios pero, queriendo ser comprensivo hacia ellos aunque de manera incomprensible para el proceso resultante, recomendaba que se les diese un trato correcto (Scalercio, 2018). Lo que de ninguna manera cuestionaba era el derecho de los colonos a mantener la propiedad de la tierra:

Si se coloniza donde haya salvajes, no solo se les atraiga con menudencias y baratijas, sino que se les utilice con equidad y magnanimidad, aunque con la vigilancia adecuada; y no se gane su favor ayudándoles a invadir a sus enemigos, aunque su defensa no sea errónea; envíese con frecuencia a algunos de ellos por los territorios de la colonia para que puedan ver cómo están en mejores condiciones que sus propios terrenos y encómieselos cuando regresen. Cuando la 
colonia se sienta fuerte, entonces es tiempo de colonizar con mujeres y también con hombres; para que la colonia pueda expandirse con nuevas generaciones y no esté siempre escasa por su falta. La mayor malignidad del mundo es abandonar o desatender una colonia una vez que ya está avanzada; porque, además de la deshonra, convertirá en culpables a muchas gentes que merecen compasión (Bacon, 1980: 143-144).

Se puede considerar esta situación como de «cordial neutralidad» (Clarke, 2008: 374), pero habría que recordar lo que tiene de circunstancial. Unos años antes, Bacon había asociado la grandeza de las naciones con el aprovechamiento de las ocasiones para la guerra que les ofrecía la ayuda a los aliados:

Que les rueguen pero estén dispuestos a prestar ayuda y socorros a sus confederados, como hicieron siempre los romanos; hasta tal punto que, como los confederados tenían ligas defensivas con otros Estados distintos y una vez bajo amenaza de invasión les pidieran ayuda muy seriamente, entonces los romanos eran los más avanzados y no dejaban que ningún otro Estado tuviera el honor de prestar esa ayuda (Bacon, 1980: 130-131).

Por lo demás, lo relevante de la situación colonial no es esa recomendación de no intervenir en los conflictos de los indígenas. Mucho más importante es que muestra la voluntad de no mezclarse con ellos, de no reconocerles la propiedad de sus tierras y de ampliar estas cuando la prosperidad del asentamiento lo permita. No deja de ser sintomático que esta última no se exprese en términos económicos sino de fuerza: «Cuando la colonia se sienta fuerte».

\section{UTOPÍA CIENTÍFICA Y RAZÓN CONSERVADORA}

Dada la familiaridad de Bacon con América y las colonias, no sorprende que situara cerca de allí, como Moro su Utopía, ese nuevo mundo feliz que denomina la Nueva Atlántida. El barco que arriba a sus costas sale de Perú rumbo a China y Japón. Cruza el mar del Sur, pero cuando llevan cinco meses de navegación este no se muestra como un océano pacífico, sino turbulento y caprichoso: sus vientos hacen imposible una travesía normal y los marineros son arrastrados hacia el norte. Cuando todo parece perdido encuentran su salvación en un puerto de una hermosa ciudad llamada Bensalem. El primer contacto con un representante de la población se realiza en el mismo navío, que no puede atracar hasta ser autorizado, según lee su alarmada tripulación en un pergamino que se les entrega. 
Bacon, por tanto, parece reconocer el protagonismo español en los descubrimientos y en el dominio de los mares. Sitúa su sociedad ideal en el océano entre América y Asia, que se ha denominado el lago español, aunque lo cierto es que en este no dejó de manifestarse la amenaza de los barcos ingleses (Spate, 2006; Bradley, 1988). Reconoce esa familiaridad sirviéndose de marinos españoles o del Imperio español, puesto que señala su paisanaje con Colón (Bacon, 1996: 272). Además, el Canciller parece querer reconocer la universalidad del castellano en su tiempo cuando indica que el pergamino que les entregan los atlantes que se acercan al barco a su llegada iba escrito en hebreo, griego, latín y español, el mismo idioma en el que contesta la tripulación del navío y que utilizarán a partir de entonces (ibid:: 236). También el atuendo que luce el sabio de la Casa de Salomón que regresa a Bensalem parece una concesión al predominio de la moda española en la época: lleva, entre otras cosas, «el sombrero, como un casco o montera española» (ibid.: 261).

A estos datos textuales se podrían unir otros de índole más especulativa, como la relación de Bacon con el cosmógrafo español Pedro Sarmiento de Gamboa, prisionero en la corte inglesa de Isabel I, con el que dialoga en latín delante de sus cortesanos (Sarmiento de Gamboa, 1866: 411; Barros Franco, 1981: 15). No obstante, «Isabel I, lord Burghley y sir Robert Cecil dominaban el español», por lo que no parecía necesario que tuvieran que recurrir al latín para comunicarse, salvo que la reina "que es elegante» en ese idioma, según informó Sarmiento, deseara mostrar su erudición o que la conversación fuera más accesible para sus súbditos (Elliott, 2010: 59). Bacon no solo se encontraba entre ellos, sino que pudo tener relación directa con Sarmiento pues, como sobrino del primer ministro lord Burghley, pudo haber estado presente durante la visita que le hizo, donde «me mostraste en tu casa antigüedades y documentos» (Eichmann y Zuleta, 2016: 40).

Tal vez no sea ajeno a algunas de las claves de la redacción de la Nueva Atlántida que, como ya se ha dicho, Sarmiento creía en su existencia (Robles, 2007; Tord, 1999). Este descubrió junto con Álvaro de Mendaña, en una expedición que sale de Perú, como la del relato de Bacon, unas islas en el Pacífico a las que dieron el nombre de Salomón. En los escritos de Bacon se honra la figura del rey sabio (I, CXXIX; Bacon, 1985: 183). Además, su nombre es una forma de alusión habitual a Jacobo I (Albanese, 1990: 516), a quien se elogia al inicio de La gran restauración con una dedicatoria elocuente: «Vos, que en tantos aspectos recordáis a Salomón» (Bacon, 1985: 46), aunque el Canciller mantuvo con él una ambivalente relación (Jowitt, 2002: 139-143). Asimismo, durante su reinado estuvo presente la idea de construir un palacio según el modelo del Templo de Salomón, el mismo que había inspirado, por cierto, el monasterio de El Escorial (Elliott, 2010: 62). No debe sorprender que el monarca más honrado de la Nueva Atlántida fuera Saloma (Solamona) 
(Bacon, 1996: 250). Tampoco el éxito de la Casa de Salomón y la inspiración que significó para el siglo siguiente (Jalobeanu, 2009). Todo ello autoriza a pensar en una concesión de la ficción literaria a la realidad política.

También son importantes las coincidencias entre el pensamiento de Bacon y los escritos del piloto Pedro Fernández de Quirós en cuanto afecta a la religión, el interés por el Pacífico, la pretensión de fundar una ciudad ideal regida por un gobierno cristiano y político, una ciudad formada por virtuosos sabios y trabajadores, la crítica de la escolástica, la afinidad entre ambos por la recopilación de datos de la naturaleza, etc. (Pimentel, 2003: 92-93). No hay que olvidar que el octavo de los Memoriales de Fernández de Quirós sería publicado fuera de la península en 1609 y en distintos idiomas, para satisfacción del resto de las cortes europeas, ansiosas de recabar noticias de los descubrimientos hispanos (Gómez-Tabanera, 1998: 253). Sin embargo, incluso si llegó a leerlo, Bacon no aceptó su pretensión de haber descubierto lo que después sería Australia, pues todavía en 1620 consideraba que la historia natural debería aclarar "si existe algún continente austral o solamente islas» (Bacon, 1985: 380).

En definitiva, las claves hispanas de la utopía de Bacon no pueden negarse (Cañizares-Esguerra, 2006: 19). Además, la Nueva Atlántida presenta propiedades que tienen mucho que ver con las preocupaciones políticas y teóricas de su autor, en absoluto ajenas a la monarquía hispánica. De inicio, no debe pasar desapercibido que Bacon sitúa la Nueva Atlántida en el norte del mar del Sur, esto es, en un espacio del océano Pacífico en gran parte inexplorado y desconocido para los mismos españoles. Tal vez por esta imprecisión geográfica, el supuesto territorio podía albergar el sueño de su autor para Inglaterra: nuevos dominios que equipararan a su país con su rival hispano.

Pero lo más novedoso de la utopía baconiana se desarrolla en el terreno del conocimiento. El Canciller se sirve de la ciencia para sentar las bases de su utopía, proponiendo un modelo de organización social que supone una reorganización de la sociedad y una renovación de los valores morales existentes. Si América, la antigua Atlántida, perdió sus hombres más sabios y quedó prisionera de la ignorancia para los siglos posteriores tras el diluvio que la asoló, la Nueva Atlántida ha convertido la sabiduría en su rasgo más valioso y característico. El lugar privilegiado del conocimiento garantizaría, si se diera en la realidad su descubrimiento, una relación con los atlantes inversa a la que han mantenido los españoles con los indios. Así lo demuestra la superioridad de su marina frente a cualquier otra (Bacon, 1996: 250), así como la de sus cańones y máquinas de todas clases (Bacon, 1996: 271). Sin embargo, no es el poder militar o no es, sobre todo, el poder militar el que destaca el autor de la Nueva Atlántida. Los españoles encuentran en esa tierra lo contrario que en América: frente a la rudeza de sus habitantes, su superior conocimiento; en 
lugar de su ausencia de vestidos y modales, la riqueza de atuendos y la delicadeza de formas. También la respuesta que se encuentran a su llegada es muy diferente a la que les dio el Nuevo Mundo: no solo una sociedad refinada en sus valores sociales, sino también una comunidad que los acoge con la religión del amor. Aun así, parece exagerado querer ver en ello una prefiguración de la superioridad de Gran Bretaña y su identificación con la ciencia (Weinberger, 1976: 877).

El influjo de la Nueva Atlántida se va a plasmar en la estrecha conexión entre ciencia y organización social que van a mostrar todas las utopías a partir de ella (Elena, 1986b: 67). Ya se ha dicho que para Bacon saber y poder están relacionados no tanto porque el primero proporcione el poder político, sino porque permite el poder sobre la naturaleza, poder para actuar en el mundo. También en la Nueva Atlántida existe una institución, la Casa de Salomón o Colegio de las Obras de Seis Días, que agrupa a los sabios del lugar y que "está dedicada al estudio de las obras y criaturas de Dios» (Bacon, 1996: 252). Es decir, también en el mundo ideal y acaso allí más que en ningún otro lugar, puesto que se trata de una sociedad sońada, la adquisición de conocimientos de todo tipo es un objetivo irrenunciable de los humanos, hasta convertirse a través de sus efectos en el centro de la vida social de la comunidad.

Se ha señalado que la inspiración más próxima de la Casa de Salomón podría ser la sevillana Casa de Contratación, donde se entrenaban pilotos, se diseñaban mapas y se centralizaba la recogida de todo tipo de datos sobre el Nuevo Mundo para su aprovechamiento y aplicación (Cañizares-Esguerra, 2006: 19; véase Grafton, 2001). La admiración inglesa por la misma no nace con Bacon, sino que se remonta a mediados del siglo xvi, cuando una delegación de la Corona inglesa, con el célebre explorador Stephen Borough como máximo estandarte, pudo comprobar su funcionamiento científico y burocrático (Sánchez Martínez, 2010: 720). Tras su visita, Richard Eden y Richard Hakluyt no dejaron de estimular el interés de sus compatriotas por las exploraciones y dominios hispanos de ultramar (Elliott, 2010: 66). No obstante, es — sin duda- Bacon quien da aires literarios al modelo sevillano: también la Casa de Salomón persigue "el estudio de la verdadera naturaleza de todas las cosas» para alcanzar a obtener «más fruto en el empleo de ellas» (Bacon, 1996: 252, 263). La importancia del saber para los atlantes es tal que el mejor de sus monarcas quiso preservar la isla de la venida de extranjeros, pero no renunció a aprovechar los conocimientos que pudieran alcanzar. Para hacerse con ellos, envían cada doce años dos naves con tres sabios de la Casa de Salomón cada una, «cuya misión consistiría únicamente en traernos informes del estado y asuntos de los países que se les seńalaba, sobre todo de las ciencias, artes, fabricaciones, invenciones y descubrimientos de todo el mundo. Teniendo también el encargo de traernos libros, instrumentos y modelos de todas clases» (ibid.: 253). 
Bacon no se plantea, por consiguiente, el problema del aprovechamiento de los propios conocimientos por sus descubridores. No ve un problema en averiguar y apropiarse esos adelantos, como no veía dificultad alguna en que los colonos europeos aprovecharan las tierras de los nativos americanos. En este sentido se podría hablar de un colonialismo científico por parte de los sabios de la Casa de Salomón, verdaderos imperialistas del conocimiento dispuestos siempre a apoderarse de las invenciones ajenas.

La Nueva Atlántida es un texto incompleto publicado tras la muerte de Bacon. Estos caracteres impiden juzgar con seguridad sus contenidos porque tal vez su autor habría variado algunos de ellos de haberla acabado o, sencillamente, porque decidió no terminarla una vez expuesto lo que le interesaba, si es que pensaba publicarla, lo que tampoco está claro (Price, 2002). Sean cuales sean las razones que llevaron al estado actual de la obra, su parte conocida muestra la existencia de una sociedad en la que la ciencia y los técnicos ocupan un lugar privilegiado. En esta utopía se otorga la primacía al conocimiento, de manera que se sustituye la conquista de los salvajes por la de los fenómenos de la naturaleza (Albanese, 1990: 511). Aunque es evidente que ambas conquistas son muy diferentes y tienen consecuencias dispares, la segunda se asienta también sobre una forma de desposesión, a saber: que lo que no alcancen a conocer por sí mismos los sabios de la Casa de Salomón pueden apropiárselo aprovechando los descubrimientos ajenos. Por algo se ha hablado de la ambigüedad política de Bensalem (Delbourgo y Dew, 2008: 2).

La utopía escrita por Bacon muestra así que el sueño de construir un mundo mejor, incluso si se alcanza mediante la ciencia, no es ajeno a la pretensión de dominio social: «El colonialismo es más que un elemento presente dentro de la Nueva Atlántida: es un movimiento determinante en la aparición de la práctica científica moderna desde dentro de la cultura renacentista tardía» (Albanese, 1990: 505-506). Desde esa perspectiva es difícil aceptar que la concepción de la ciencia de Bacon sea pública y democrática (Rossi, 1996: 32). Más bien hay que concebirla como restringida y jerárquica (Rusu, 2010: 60). Por su parte, el dominio de unos pocos sobre una gran mayoría sirviéndose de imposiciones ideológicas, de género, morales, religiosas, etc., no está menos presente en esa concepción (Coquillette, 1992: 261). La Nueva Atlántida no deja de reflejar las preocupaciones generales de su autor, impregnando sus propuestas de cooperación en la investigación científica (Sargent, 1996: 163-164).

En definitiva, deberíamos sacar al menos tres conclusiones de lo visto: en primer lugar, la ciencia, la política y la utopía baconianas, sin dejar de presentarse como formas renovadas de contribuir a la construcción del imperio, adquirían su pleno sentido sobre el trasfondo de lo hecho por su rival hispano. En segundo lugar, la imitación selectiva y la emulación eran compatibles con 
la crítica e incluso la hostilidad, pero unas y otras pretendían alcanzar las metas atribuidas al enemigo y dotarse de los instrumentos que se considerasen más útiles para lograrlo. Por último, en tercer lugar, consideraciones como las de Bacon, que incluyen tanto imitación y rechazo como admiración y reproche, deberían servir para poner en cuestión la existencia de una leyenda negra hispana en el primer cuarto del siglo Xviı. Un análisis ajeno a ese método prejuicioso de recopilar únicamente la literatura descalificadora sobre el país debería servir para descubrir, dentro de una situación general donde abundan la ambigüedad y la complejidad, que la monarquía hispánica provocaba también respeto e incluso afán emulador entre observadores que no carecían de criterio.

\section{Bibliografía}

Acosta, J. (2008). Historial Natural y Moral de las Indias. Madrid: CSIC.

Albanese, D. (1990). The New Atlantis and the Uses of Utopia. ELH, 57 (3), 503-528. Disponible en: https://doi.org/10.2307/2873232.

Armitage, D. (2004a). The Elizabethan Idea of Empire. Transactions of the Royal Historical Society, 14, 269-277. Disponible en: https://doi.org/10.1017/S008044010400012X.

Armitage, D. (2004b). The Ideological Origins of the British Empire. Cambridge; Nueva York: Cambridge University Press.

Bacon, F. (1826). Tracts relating to Spain. En B. Montagu. The Works of Francis Bacon (pp. 203-307). London: W. Pickering.

Bacon, F. (1859). The Works of Francis Bacon. London: Parry and McMillan.

Bacon, F. (1863). Historia ventorum, Works. Boston: Houghton, Mifflin and Company.

Bacon, F. (1926) [1868]. The Advancement of Learning. Oxford: Clarendon Press.

Bacon, F. (1968). Consideraciones sobre una presunta guerra con España. En V. Morales Lezcano. La guerra contra España en la filosofía política de Sir Walter Raleigh y Francis Bacon.

Bacon, F. (1980). Ensayos. Buenos Aires: Aguilar.

Bacon, F. (1985). La gran restauración. Madrid: Alianza.

Bacon, F. (1988). El avance del saber. Madrid: Alianza Editorial.

Bacon, F. (1996). Nueva Atlántida. En T. Moro, T. Campanella y F. Bacon. Utopias del Renacimiento (pp. 233-273). Madrid: Fondo de Cultura Económica.

Barrera-Osorio, A. (2006). Experiencing Nature. The Spanish American Empire and the early Scientific Revolution. Austin: University of Texas Press.

Barrera-Osorio, A. (2008). Empiricism in the Spanish Atlantic World. En J. Delbourgo and N. Dew (eds.). Science and Empire in the Atlantic World (pp. 177-202). New York; London: Routledge. Disponible en: https://doi.org/10.4324/9780203933848-11.

Barros Franco, J. (1981). Los últimos años de Pedro Sarmiento de Gamboa. Boletín de la Academia Chilena de la Historia, 90, 9-28.

Bradley, P. T. (1988). La fascinación europea con el Perú y expediciones al Mar del Sur en el siglo Xvir. Revista de Indias, 48 (182-183), 257-283.

Bury, J. (1971). La idea del progreso. Madrid: Alianza. 
Camprubí, L. (2009). Traveling Around the Empire: Iberian Voyages, the Sphere, and the Atlantic Origins of the Scientific Revolution. Ë̈, 1 (2), 1-24.

Cañizares-Esguerra, J. (2006). The Colonial Iberian Roots of the Scientific Revolution. En J. Cañizares-Esguerra. Nature, Empire, and Nation. Explorations of the History of Science in the Iberian World (pp. 14-45). Stanford University Press.

Castilla Urbano, F. (2014). Introducción. En F. Castilla Urbano (ed.). Discursos legitimadores de la conquista y la colonización de América (pp. 9-20). Madrid: Universidad de Alcalá.

Castilla Urbano, F. (2015). Conquista y comercio: la visión colonial de Montesquieu. En F. Castilla Urbano (ed.). Visiones de la conquista y la colonización de las Américas (pp. 89-106). Madrid: Universidad de Alcalá.

Ceceña, R. (2010). L'experientia et l'inventio du Nouveau Monde. De l'histoire à la théorie de la connaissance de la nature. Eikasia. Revista de Filosofia, 6 (35), 67-84.

Cioranescu, A. (1983). Le Masque et le visage. Du baroque espagnol au classicisme français. Ginebra: Librairie Droz.

Clarke, M. T. (2008). Uprooting Nebuchadnezzar's Tree: Francis Bacon's Criticism of Machiavellian Imperialism. Political Research Quarterly, 61 (3), 367-378. Disponible en: https://doi.org/10.1177/1065912908318845.

Cohen, I. B. (1983). La revolución newtoniana y la transformación de las ideas cientificas. Madrid: Alianza.

Colclough, D. (2010). "The Materialls for the Building»: Reuniting Francis Bacon's Sylva Sylvarum and New Atlantis. Intellectual History Review, 20 (2), 181-200. Disponible en: https://doi.org/10.1080/17496971003783757.

Coquillette, D. R. (1992). Francis Bacon. Melsham: Edinburgh University Press.

Corcoran, P. (2018). John Locke on Native Right, Colonial Possession, and the Concept of Vacuum domicilium. The European Legacy, 23 (3), 225-250. Disponible en: https:// doi.org/10.1080/10848770.2017.1416766.

Delbourgo, J. and Dew, N. (2008). Introduction. The Far Side of the Ocean. En J. Delbourgo and N. Dew (eds.). Science and Empire in the Atlantic World (pp. 1-28). New York; London: Routledge. Disponible en: https://doi.org/10.4324/9780203933848-1.

Eamon, W. (2019). Spanish Science in the Age of New. En H. Kallendorf (ed.). A Companion to the Spanish Renaissance (pp. 473-507). Leiden; Boston: Brill. Disponible en: https:// doi.org/10.1163/9789004360372_021.

Eichmann, A. y Zuleta, J. (2016). Edición y traducción de la "Carta a lord Burghley» de Pedro Sarmiento de Gamboa. Hipogrifo, 4 (1), 23-42. Disponible en: https://doi. org/10.13035/H.2016.04.01.03.

Elena, A. (1983). Física y filosofía en el siglo xvir: la Royal Society de Londres y el programa baconíano. Contextos, 1 (2), 105-125.

Elena, A. (1986a). La cuestión nacionalista y la fundación de la Royal Society: el grupo comeniano. En S. Onega (ed.). Estudios literarios ingleses. Renacimiento y Barroco (pp. 499-518). Madrid: Cátedra.

Elena, A. (1986b). Utopías científicas del siglo xvir: A description of the famous kingdome of Macaria. Llull, 9, 65-80.

Elliott, J. (2010). Aprendiendo del enemigo: Inglaterra y España en la Edad Moderna. En J. Elliott. España, Europa y el mundo de ultramar (1500-1800) (pp. 55-85). Madrid: Taurus. 
Farrington, B. (1971). Francis Bacon, filósofo de la revolución industrial. Madrid: Editorial Ayuso.

Ferraz Martínez, A. (2000). La apetencia humana de historias ficticias. Ecos de una tesis de Francis Bacon en el xix (con una coda del xx). En F. Sevilla y C. Alvar (eds.). Actas del XIII Congreso de la Asociación Internacional de Hispanistas. Madrid, 1998 (pp. 177-186). Madrid: Editorial Castalia.

Fuchs, B. (2013). The Poetics of Piracy. Emulating Spain in English Literature. Philadelphia: University of Pennsylvania Press. Disponible en: https://doi.org/10.9783/97808122 07767.

García, R. (1992). La leyenda negra. Historia y opinión. Madrid: Alianza Editorial.

Gascoigne, J. (2009). The Royal Society, natural history and the peoples of the "New World(s)», 1660-1800. British Journal of the History of Science, 42 (4), 539-562. Disponible en: https://doi.org/10.1017/S0007087409002210.

Gascoigne, J. (2012). Crossing the Pillars of Hercules: Francis Bacon, the Scientific Revolution and the New World. En O. Gal y R. Chen-Morris (eds.). Science in the Age of Baroque (pp. 217-238). Dordrecht: Springer. Disponible en: https://doi.org/10.1007/ 978-94-007-4807-1_9.

Gaukroger, S. (2004). Francis Bacon and the Transformation of Early-Modern Philosophy. Cambridge: Cambridge University Press.

Gerbi, A. (1993). La disputa del Nuevo Mundo. Historia de una polémica 1750-1900. México: Fondo de Cultura Económica.

Gómez-Tabanera, J. M. (1998). Sir Thomas More (1478-1535), Pedro Fernández de Quirós (1562-1615) y Sir Francis Bacon (1561-1626), o la forja de una utopía política en la Inglaterra del siglo XvII. En J. Whicker (coord.). Estudios áureos I. Actas del XII Congreso de la Asociación Internacional de Hispanistas 21-26 de agosto de 1995 (pp. 249-56). Birmingham: Department of Hispanic Studies.

González Díaz, S. (2012). Genealogía de un origen: Túbal, el falsario y la Atlántida en la Historia de los Incas de Pedro Sarmiento de Gamboa. Revista de Indias, 72 (255), 497-526. Disponible en: https://doi.org/10.3989/revindias.2012.016.

Grafton, A. (2001). Where Was Salomon's House? Ecclesiastical History and the Intellectual Origins of Bacon's New Atlantis. En H. Jaumann (ed.). Die europäische Gelehrtenrepublik im Zeitalter des Konfessionalismus (pp. 21-38). Wiesbaden: Harrassowitz.

Granada, M. Á. (1982). La reforma baconiana del saber: milenarismo cientifista, magia, trabajo y superación del escepticismo. Teorema: Revista Internacional de Filosofía, 12 (1-2), 71-95.

Hart, J. (2001). Representing the New World: the English and French uses of the example of Spain. New York: Palgrave. Disponible en: https://doi.org/10.1057/9780312299200.

Herrera, A. de (1601). Historia general de los hechos de los castellanos en las Islas y Tierra Firme del Mar Océano, Década I. Madrid: Emplenta Real.

Hillgarth, J. N. (2000). The Mirror of Spain, 1500-1700: The Formation of a Myth. Ann Arbor: University of Michigan Press. Disponible en: https://doi.org/10.3998/mpub.16832.

Hutton, S. (2002). Persuasions to science: Baconian rhetoric and the New Atlantis. En B. Price (ed.). Francis Bacon's NEW ATLANTIS New interdisciplinary essays (pp. 48-59). New York: Manchester University Press. 
Irving, S. (2006). «In a pure soil»: Colonial anxieties in the work of Francis Bacon. History of European Ideas, 32, 249-262. Disponible en: https://doi.org/10.1016/j.histeuroideas.2006.03.001.

Irving, S. (2007). An empire restored: America and the Royal Society of London in the Restoration. En C. Armstrong, R. Fagge y T. J. Lockley (eds.). America in the British Imagination (pp. 27-47). Newcastle: Cambridge Scholars Publishing.

Jalobeanu, D. (2009). The Fascination of Solomon's House in Seventeenth Century England: Baconianism Revisited. En V. Alexandrescu (ed.). Branching Off. The Early Moderns in Quest for the Unity of Knowledge (pp. 225-255). Bucarest: Zeta Books. Disponible en: https://doi.org/10.7761/9789731997438_10.

Jalobeanu, D. (2014). A Natural History of the Heavens: Francis Bacon's Anti-Copernicanism. En The Making of Copernicus (pp. 64-87). Leiden: Brill. Disponible en: https:// doi.org/10.1163/9789004281127_005.

Jowitt, C. (2002). «Books will speak plain?». Colonialism, Jewishness and politics in Bacon's New Atlantis. En B. Price (ed.). Francis Bacon's NEW ATLANTIS New interdisciplinary essays (pp. 129-155). Manchester: Manchester University Press.

Koyré, A. (1999). Del mundo cerrado al universo infinito. Madrid: Siglo XXI.

Kuhn, T. S. (1982). La tradición matemática y la tradición experimental en el desarrollo de la física. En T. S. Kuhn. La tensión esencial. Estudios selectos sobre la tradición y el cambio en el ámbito de la ciencia (pp. 56-90). Madrid: Fondo de Cultura Económico.

Kusukawa, S. (1996). Bacon's classification of knowledge. En M. Peltonen (ed.). The Cambridge Companion to Bacon (pp. 47-74). Cambrigde: Cambridge University Press. Disponible en: https://doi.org/10.1017/CCOL052143498X.003.

Lamb, U. (1985). Nautical scientists and their clients in Iberia (1508-1624): science from imperial perspective. Separata de Revista da Universidade de Coimbra, 32, 49-61.

López de Gómara, F. (1978). Historia General de las Indias y vida de Hernán Cortés. Caracas: Biblioteca Ayacucho.

Macmillan, K. (2011). Benign and Benevolent Conquest? The Ideology of Elizabethan Atlantic Expansion Revisited. Early American Studies: An Interdisciplinary Journal, 9 (1), 32-72. Disponible en: https://doi.org/10.1353/eam.2011.0009.

Madrid, C. M. (2010). La representación de la técnica y de la ciencia entre los siglos XVI y XVIII en la colección del Museo del Prado. Llull, 33 (72), 269-287.

Madrid, C. M. (2013). España y la Revolución Científica: estado de la cuestión de una polémica secular. Circumscribere, 13, 1-28.

Maltby, W. S. (1982). La Leyenda Negra en Inglaterra. Desarrollo del sentimiento antihispánico, 1558-1660. México: Fondo de Cultura Económica.

Manzo, S. (2010). Utopian science and empire. Notes on the Iberian background of Francis Bacon's. Studii de ştiinŃă şi cultură, 4, 111-128.

Manzo, S. A. (2001). Experimentación, instrumentos científicos y cuantificación en el método de Francis Bacon. Manuscrito, 24 (1), 49-84.

Manzo, S. A. (2014). Historia civil y poesía, certeza y verdad en Francis Bacon. Anales del Seminario de Historia de la Filosofía, 31 (2), 373-394. Disponible en: https://doi. org/10.5209/rev_ASHF.2014.v31.n2.47574.

Maquiavelo, N. (1978). El príncipe. Barcelona: Bruguera. 
Maquiavelo, N. (2005). Discursos sobre la primera década de Tito Livio. Madrid: Alianza.

Maravall, J. A. (1986). Antiguos y Modernos. Visión de la historia e idea de progreso hasta el Renacimiento. Madrid: Alianza.

Marías, J. (1985). España inteligible. Razón histórica de las Españas. Madrid: Alianza Editorial.

Martin, J. (2007). Francis Bacon, the State, and the Reform of Natural Philosophy. New York: Cambridge University Press.

Montesquieu, Ch. L. de Secondat, baron de (1980). Del espiritu de las leyes. Madrid: Tecnos.

Morales Lezcano, V. (1968). La guerra contra España en la filosofía política de Sir Walter Raleigh y Francis Bacon. Revista de Indias, 28, 111.

Mori, G. (2016). Mathematical subtleties and scientific knowledge: Francis Bacon and mathematics, at the crossing of two traditions. The British Journal for the History of Science, 50 (1), 1-21. Disponible en: https://doi.org/10.1017/S0007087416001163.

Nieto Olarte, M. (2009). Ciencia, imperio, modernidad y eurocentrismo: el mundo atlántico del siglo xvi y la comprensión del Nuevo Mundo. Historia Crítica, 12-32. Disponible en: https://doi.org/10.7440/histcrit39E.2009.01.

Nisbet, R. (1981). Historia de la idea de progreso. Barcelona: Gedisa.

Peltonen, M. (1992). Politics and Science: Francis Bacon and the True Greatness of States. The Historical Journal, 35 (2), 279-305. Disponible en: https://doi.org/10.1017/ S0018246X00025802.

Peltonen, M. (1996). Bacon's political philosophy. En M. Peltonen (ed.). The Cambridge Companion to Bacon (pp. 283-310). Cambridge: Cambridge University Press. Disponible en: https://doi.org/10.1017/CCOL052143498X.012.

Pimentel, J. (2001). The Iberian Vision: Science and Empire in the Framework of a Universal Monarchy, 1500-1800. Osiris, 15, 17-30. Disponible en: https://doi.org/ $10.1086 / 649316$.

Pimentel, J. (2003). Testigos del mundo. Ciencia, literatura y viajes en la Ilustración. Madrid: Marcial Pons Historia.

Portuondo, M. M. (2009). Secret Science. Spanish Cosmography and the New World. Chicago; London: The University of Chicago Press. Disponible en: https://doi.org/10.7208/ chicago/9780226675374.001.0001.

Price, B. (2002). Introduction. En B. Price (ed.). Francis Bacon's NEW ATLANTIS New interdisciplinary essays (pp. 1-27). Manchester; New York: Manchester University Press. Disponible en: https://doi.org/10.9760/MUPOA/9780719060519.

Rees, G. (1981). An Unpublished Manuscript by Francis Bacon: Sylva Sylvarum Drafts and Other Working Notes. Annals of Science, 38, 377-412. Disponible en: https://doi. org/10.1080/00033798100200291.

Robles, J. F. (2007). La Atlántida en América: ideología de un mito (siglos XVI y XvII). Armas y Letras, 57, 57-63.

Rossi, P. (1970). La idea de progreso científico. En P. Rossi. Los filósofos y las máquinas, 14001700 (pp. 67-97). Barcelona: Labor.

Rossi, P. (1990). Francis Bacon: de la magia a la ciencia. Madrid: Alianza.

Rossi, P. (1996). Bacon's idea of science. En M. Peltonen (ed.). The Cambridge Companion to Bacon (pp. 25-46). Cambridge: Cambridge University Press. Disponible en: https://doi. org/10.1017/CCOL052143498X.002. 
Rusu, D. C. (2010). Virtues and Collaborative Research in Solomon's House. Studii de stiinN si cultură, $6(4,23), 59-73$.

Rusu, D. C. and Lüthy, C. (2017). Extracts from a paper laboratory: the nature of Francis Bacon's Sylva sylvarum. Intellectual History Review, 27 (2), 171-202. Disponible en: https://doi.org/10.1080/17496977.2017.1292020.

Sánchez Martínez, A. (2010). La institucionalización de la cosmografía americana: la Casa de la Contratación de Sevilla, el Real y Supremo Consejo de Indias y la Academia de Matemáticas de Felipe II. Revista de Indias, 70 (250), 715-748. Disponible en: https://doi. org/10.3989/revindias.2010.23.

Sánchez, A. y Leitão, H. (2017a). La ciencia ibérica: ‘aparte o parte de la ciencia moderna? Revista de Occidente, 433, 5-18. Disponible en: https://doi.org/10.26885/rcei.5.1.18.

Sánchez, A. y Leitão, H. (2017b). Zilsel's Thesis, Maritime Culture, and Iberian Science in Early Modern Europe. Journal of the History of Ideas, 78 (2), 191-210. Disponible en: https://doi.org/10.1353/jhi.2017.0010.

Sanchez, M. G. (2004). Anti-Spanish sentiment in English literary and political writing 15531603. Leeds: University of Leeds.

Sargent, R. M. (1996). Bacon as an advocate for cooperative scientific research. En M. Peltonen (ed.). The Cambridge Companion to Bacon (pp. 146-171). Cambridge: Cambridge University Press. Disponible en: https://doi.org/10.1017/CCOL05214349 8X.007.

Sarmiento de Gamboa, P. (1866). Sumaria relación de Pedro Sarmiento de Gamboa, Gobernador y Capitán General del Estrecho de Magallanes, acerca de las poblaciones en él hechas y por hacer, dirigida a S. M. (15 de setiembre de 1589). En Colección de documentos inéditos relativos al descubrimiento, conquista y organización de las antiguas posesiones españolas en América y Oceanía (pp. 286-420). Madrid.

Scalercio, M. (2018). Dominating nature and colonialism. Francis Bacon's view of Europe and the New World. History of European Ideas, 44 (8), 1076-1091. Disponible en: https:// doi.org/10.1080/01916599.2018.1512282.

Scanlan, T. (2008). Las Casas and the American Literature Survey. En S. Arias and E. M. Merediz (eds.). Approaches to Teaching the Writings of Bartolomé de las Casas (pp. 218-223). New York: MLAA.

Schaub, J. F. (2003). La France espagnole. Les racines hispaniques de l'absolutisme français. Paris: Éditions du Seuil. Disponible en: https://doi.org/10.14375/NP.9782020407694.

Serjeantson, R. (2002). Natural knowledge in the New Atlantis. En B. Price (ed.). Francis Bacon's NEW ATLANTIS New interdisciplinary essays (pp. 82-105). Manchester: Manchester University Press.

Serjeantson, R. (2014). Francis Bacon, colonization, and the limits of Atlanticism. En R. Serjeantson. Nature, Politics, and the Imagination in the Thought of Francis Bacon (15611626). Berkeley: University of California. Disponible en: https://bit.ly/3sbyeSg.

Shapin, S. (1996). The Scientific Revolution. Chicago; London: The University of Chicago Press. Disponible en: https://doi.org/10.7208/chicago/9780226750224.001.0001.

Solís Santos, C. (2018). El hombre que quería saberlo todo. Bacon entre los científicos del siglo Xvir. Asclepio. Revista de Historia de la Medicina y de la Ciencia, 70 (2), 228. Disponible en: https://doi.org/10.3989/asclepio.2018.12. 
Spate, O. H. K. (2006). El lago español. Annu Press. Disponible en: https://doi.org/10.26530/ OAPEN_459096.

Tord, L. E. (1999). Platón, la Atlántida y los cronistas del Perú. En T. Hampe Martínez (ed.). La tradición clásica en el Perú virreinal (pp. 35-45). Lima: UNMSM Fondo Editorial.

Valle, I. del (2013). From José de Acosta to the Enlightenment: Barbarians, Climate Change and (Colonial) Technology as the End of History. The Eighteenth Century, 54 (4), 435-459. Disponible en: https://doi.org/10.1353/ecy.2013.0042.

Villaverde, M. J. y Castilla, F. (2016). La sombra de la leyenda negra. Madrid: Tecnos.

Weinberger, J. (1976). Science and Rule in Bacon's Utopia: An Introduction to the Reading of the New Atlantis. The American Political Science Review, 70 (3), 865-885. Disponible en: https://doi.org/10.2307/1959872.

White, H. B. (1958). Bacon's Imperialism. The American Political Science Review, 52 (2), 470-489. Disponible en: https://doi.org/10.2307/1952328.

Zagorin, P. (1999). Francis Bacon. Princeton: Princeton University Press. Disponible en: https://doi.org/10.1515/9780691221625. 
